\title{
GMR
}

\section{Association between the polymorphisms in the ATP-binding cassette genes $A B C B 1$ and $A B C C 2$ and the risk of drug-resistant epilepsy in a Chinese Han population}

T. Xue and Z.N. Lu

Department of Neurology, Renmin Hospital of Wuhan University, Wuhan, China

Corresponding author: Z.N. Lu

E-mail: xuetao_whu@163.com

Genet. Mol. Res. 15 (4): gmr15048752

Received May 2, 2016

Accepted October 18, 2016

Published November 25, 2016

DOI http://dx.doi.org/10.4238/gmr15048752

Copyright (C) 2016 The Authors. This is an open-access article distributed under the terms of the Creative Commons Attribution ShareAlike (CC BY-SA) 4.0 License.

ABSTRACT. Epilepsy is a common disease of the nervous system; approximately $20-30 \%$ of all patients with epilepsy are reported resistant to antiepileptic drugs. $\mathrm{ABCB} 1$ and $\mathrm{ABCC} 2$ are members of ATP-binding cassette transporter (ABC) family that is involved in the excretion of antiepileptic drugs. In this case-control study, we have investigated the role of $A B C B 1$ rs1045642 and rs2032582 and $A B C C 2$ rs2273697 and rs717620 single nucleotide polymorphisms in antiepileptic drug-resistance in patients with epilepsy. A total of 254 patients with epilepsy (104 drug-resistant and 150 drug-responsive) were recruited from the People's Hospital of Wuhan University between March 2013 and April 2014. The correlation between the demographic, clinical, and genotypic characteristics of the patients and risk of drug resistance was statistically analyzed. Patients with drug-resistant epilepsy were more likely to present symptomatic epilepsy $\left(\chi^{2}=22.29\right.$, $\mathrm{P}<0.001)$ compared to those with drug-responsive epilepsy. The TT genotype of the $A B C B 1$ rs 717620 polymorphism was associated with 
a higher risk of drug-resistant epilepsy compared to the CC genotype [odds ratio $(\mathrm{OR})=2.97,95 \%$ confidence interval $(\mathrm{CI})=1.11-8.29$ ]. The TT genotype of $A B C B 1$ rs717620 was also related with an increased risk of drug-resistant epilepsy $(\mathrm{OR}=2.64,95 \% \mathrm{CI}=1.03-7.13)$ compared to the $\mathrm{CC}+\mathrm{CT}$ genotype in the recessive model. Thus, our study suggests that the $A B C C 2$ rs717620 polymorphism is associated with resistance to antiepileptic drugs in Chinese patients with epilepsy.

Key words: $A B C B 1 ; A B C C 2$; Polymorphism; Antiepileptic drugs

\section{INTRODUCTION}

Epilepsy is a common disease affecting the nervous system; the estimated prevalence and morbidity rates of epilepsy are approximately $2.1-7.8 \%$ and 28.8/100,000 in China (Pi et al., 2014; Tang et al., 2014; Zhou et al., 2014). Epilepsy is caused by super-synchronous discharges from the brain neurons, resulting in sudden and repetitive short bursts of central nervous system dysfunction. Epilepsy is treated mainly by pharmaceutical drugs; while these drugs are effective in controlling the symptoms of $\sim 60 \%$ epileptic patients, approximately $20-30 \%$ of these patients have been shown to be resistant to antiepileptic drugs (Giussani et al., 2016; Huang et al., 2016). Pharmacogenetic factors may play a key role in individualized sensitivity to antiepileptic drugs. Previous studies have identified several genetic factors that are involved in drug resistance in patients with epilepsy, such as $A B C C 2$, SCN1A, SCN2A, KCNJ10, ATP1A2, and ATP1A3 (Escalante-Santiago et al., 2014; Ma et al., 2014; Guo et al., 2015; Qu et al., 2015; Wang et al., 2015).

Multidrug transporters play a major role in the drug resistance mechanism. Lazarowski and Czornyj (2011) reported that overexpression of multidrug transporters could result in excessive transport (and hence, elimination) of antiepileptic drugs from the lesions, thereby influencing the on-site concentration and effect of the drug. The ATP-binding cassette (ABC) family is a multidrug transporter family; ABCB1 (P-glycoprotein, P-gp) is an important member of the $\mathrm{ABC}$ family that was among the first to be identified (Begley, 2004). High P-gp expression could result in the transfer of lipid-soluble antiepileptic drugs out of the brain tissue, reducing the concentration of antiepileptic drugs in the blood and decreasing their efficacy (Akamine et al., 2012). ABCC2 is another member of the ABC family that is involved in the excretion of antiepileptic drugs (Urry et al., 2009; Subenthiran et al., 2013b). Single nucleotide polymorphisms (SNPs) in $A B C B 1$ and $A B C C 2$ could influence the expression and functions of the resultant proteins, and may be associated with drug resistance in patients with epilepsy. Previous studies have reported a correlation between the $A B C B 1$ rs 1045642 and rs2032582 and $A B C C 2$ rs2273697 and rs717620 polymorphisms and drug resistance in patients with epilepsy; however, the results of these studies are inconsistent (Keangpraphun et al., 2015; Li et al., 2015; Yu et al., 2015; Zhou et al., 2015). In this case-control study, the role of $A B C B 1$ rs 1045642 and rs2032582 and $A B C C 2$ rs2273697 and rs 717620 SNPs in the resistance to antiepileptic drugs was investigated in patients with epilepsy.

\section{MATERIAL AND METHODS}

\section{Subjects}

A hospital-based case-control design was employed in this study. A total of 254

Genetics and Molecular Research 15 (4): gmr15048752 
patients with epilepsy were recruited from the People's Hospital of Wuhan University between March 2013 and April 2014. Patients conforming to the following criteria were included in this study: Han Chinese, aged between 5 and 80 years, and confirmed to be epileptic based on the diagnostic criteria provided by the International League against Epilepsy in 1981. Patients without serious adverse reactions, poor drug-use adherence, and end-stage liver or kidney diseases were excluded from the study.

All included patients were administered antiepileptic drugs within one year prior to enrollment. Response to antiepileptic drugs was characterized by a lack of epileptic seizures after drug administration. Resistance to antiepileptic drugs was characterized by at least four episodes of epileptic seizure despite receiving at least three types of antiepileptic drugs over a one-year period prior to the study. Based on the effective treatment criteria, 104 patients showed resistance to antiepileptic drugs, whereas 150 patients showed a positive response to antiepileptic drugs.

The clinical variables, including gender, age, use of antiepileptic drugs, body mass index, type of seizures, and etiology of the disease, were collected from the patient medical records. Written informed consent was obtained from all subjects prior to enrollment. The procedures employed in this study were approved by the Ethics Committee of the People's Hospital of Wuhan University.

\section{DNA extraction and genotyping}

Peripheral blood $(5 \mathrm{~mL})$ was collected from each subject in vacuum tubes containing $5 \%$ ethylenediaminetetraacetic acid. DNA was extracted from these samples using the TIANamp Blood DNAkit(Tiangen, Beijing, China) according to the manufacturer instructions. The $A B C B 1$ rs 1045642 and rs2032582 and $A B C C 2$ rs2273697 and rs717620 polymorphisms were genotyped by polymerase chain reaction-restriction fragment length polymorphism (PCR-RFLP). The forward and reverse primer sequences were designed as for PCR analysis as follows: $A B C B 1$ rs 1045642: 5'-TGTTTTCAGCTGCTTFATGG-3' and 5'-AAGGCATGTATGTTGGCCTC-3'; $A B C B 1$ rs2032582: 5'-CTGGACAAGCACTGAAAGATAAGA-3' and 5'-TGGCTTTGCTAC TTTCTGTAAGTT-3'; ABCC2 rs2273697: 5'-GGGCAAAGAAGTGTGTGGAT-3' and 5'-AC ATCAGGTTCACTGTTTCTCCCA-3'; and $A B C C 2$ rs717620: 5'-TAAATGGTTGGGATGAA AGG-3' and 5'-GCTTTAGACCAATTGCACATC-3'.

The amplification was performed in a $20-\mu \mathrm{L}$ reaction mixture comprising $2 \mu \mathrm{L}$ 10X PCR Buffer, $1 \mu \mathrm{L}$ dNTP $(2.5 \mathrm{mM}), 0.4 \mu \mathrm{L}$ forward primer $(10 \mu \mathrm{M}), 0.4 \mu \mathrm{L}$ reverse primer $(10 \mu \mathrm{M}), 0.2 \mu \mathrm{L}$ rTaq enzyme $(5 \mathrm{U} / \mu \mathrm{L}), 1 \mu \mathrm{L}$ gDNA, and $15 \mu \mathrm{L} \mathrm{ddH}_{2} \mathrm{O}$. The $A B C B 1$ rs 1045642 and rs2032582 and $A B C C 2$ rs2273697 and rs717620 polymorphisms were amplified as summarized in Table 1. Restriction digestion was performed using a $20-\mu \mathrm{L}$ digestion mixture comprising $2 \mu \mathrm{L} 10 \mathrm{X}$ PCR buffer, $0.5 \mu \mathrm{L}$ restriction enzyme, and $10 \mu \mathrm{L}$ PCR amplified mixture, and $7.5 \mu \mathrm{L} \mathrm{ddH_{2 }} \mathrm{O}$. The enzyme-digested products were electrophoresed on an agarose gel.

\section{Statistical analysis}

The differences in demographic and clinical variables between patients and controls were analyzed by the Student $t$-test and chi-square test.

Genetics and Molecular Research 15 (4): gmr15048752 


\begin{tabular}{|c|c|c|}
\hline Gene polymorphism & Restriction enzyme & Amplification reaction \\
\hline$A B C B 1$ rs 1045642 & BpiI & $\begin{array}{l}\text { Initial denaturation at } 98^{\circ} \mathrm{C} \text { for } 5 \mathrm{~min} ; 36 \text { cycles at } 98^{\circ} \mathrm{C} \text { for } 30 \mathrm{~s}, 58^{\circ} \mathrm{C} \text { for } 30 \mathrm{~s} \text {, and } 72^{\circ} \mathrm{C} \text { for } 30 \mathrm{~s} \text {; and a } \\
\text { final extension at } 72^{\circ} \mathrm{C} \text { for } 5 \mathrm{~min}\end{array}$ \\
\hline$A B C B 1$ rs 2032582 & NcoI & $\begin{array}{l}\text { Initial denaturation at } 98^{\circ} \mathrm{C} \text { for } 5 \mathrm{~min} ; 36 \text { cycles at } 98^{\circ} \mathrm{C} \text { for } 30 \mathrm{~s}, 54^{\circ} \mathrm{C} \text { for } 30 \mathrm{~s} \text {, and } 72^{\circ} \mathrm{C} \text { for } 30 \mathrm{~s} \text {; and a } \\
\text { final extension at } 72^{\circ} \mathrm{C} \text { for } 5 \mathrm{~min}\end{array}$ \\
\hline$A B C C 2$ rs 2273697 & $B s i \mathrm{EI}$ & $\begin{array}{l}\text { Initial denaturation at } 98^{\circ} \mathrm{C} \text { for } 5 \mathrm{~min} ; 36 \text { cycles at } 98^{\circ} \mathrm{C} \text { for } 30 \mathrm{~s}, 56^{\circ} \mathrm{C} \text { for } 30 \mathrm{~s} \text {, and } 72^{\circ} \mathrm{C} \text { for } 30 \mathrm{~s} \text {; and a } \\
\text { final extension at } 72^{\circ} \mathrm{C} \text { for } 5 \mathrm{~min}\end{array}$ \\
\hline$A B C C 2$ rs 717620 & Bspl43I & $\begin{array}{l}\text { Initial denaturation at } 98^{\circ} \mathrm{C} \text { for } 5 \mathrm{~min} ; 36 \text { cycles at } 98^{\circ} \mathrm{C} \text { for } 30 \mathrm{~s}, 56^{\circ} \mathrm{C} \text { for } 30 \mathrm{~s} \text {, and } 72^{\circ} \mathrm{C} \text { for } 30 \mathrm{~s} \text {; and a } \\
\text { final extension at } 72^{\circ} \mathrm{C} \text { for } 5 \mathrm{~min}\end{array}$ \\
\hline
\end{tabular}

Departure of the $A B C B 1$ rs1045642 and rs2032582 and $A B C C 2$ rs2273697 and rs71762 polymorphism genotype frequencies from the Hardy-Weinberg equilibrium (HWE) was calculated using the Pearson $\chi^{2}$ test. The relationships between the $A B C B 1$ rs 1045642 and rs2032582 and $A B C C 2$ rs2273697 and rs71762 polymorphisms and drug-resistant epilepsy were determined by multiple logistic regression analyses and estimated as the odds ratios (ORs) and 95\% confidence intervals (CIs). The data was statistically analyzed using SPSS v.16.0 (SPSS Inc., Chicago, IL, USA). Differences with P values $<0.05$ were considered statistically significant.

\section{RESULTS}

The demographic and clinical variables of the investigated subjects are summarized in Table 2. The mean age of patients with drug-resistant and drug-responsive epilepsy was $7.60 \pm$ 15.82 and $7.2 \pm 16.14$, respectively. Patients with drug-resistant and drug-responsive epilepsy included $61(58.65 \%)$ and $84(56.00 \%)$ males and $43(41.35 \%)$ and $66(44.00 \%)$ females, respectively. Patients with drug-resistant epilepsy were more likely to present symptomatic epilepsy $\left(\chi^{2}=22.29, \mathrm{P}<0.001\right)$ compared to those with drug-responsive epilepsy. We found no significant differences between the age $(t=0.20, \mathrm{P}=0.42)$, age at first onset $(t=1.49, \mathrm{P}=$ $0.07)$, gender $\left(\chi^{2}=0.18, \mathrm{P}=0.67\right)$, and type of seizures $\left(\chi^{2}=3.54, \mathrm{P}=0.17\right)$ in the two groups.

Table 2. Demographic and clinical variables of epileptic patients.

\begin{tabular}{|c|c|c|c|c|c|c|}
\hline Variables & Drug-resistant $(\mathrm{N}=104)$ & $\%$ & Drug-responsive $(\mathrm{N}=150)$ & $\%$ & Chi-square test & $\mathrm{P}$ value \\
\hline Mean age, years & $7.60 \pm 15.82$ & & $7.2 \pm 16.14$ & & 0.20 & 0.42 \\
\hline Age at first onset, years & $2.15 \pm 2.70$ & & $2.65 \pm 2.58$ & & 1.49 & 0.07 \\
\hline \multicolumn{7}{|l|}{ Gender } \\
\hline Male & 61 & 58.65 & 84 & 56.00 & & \\
\hline Female & 43 & 41.35 & 66 & 44.00 & 0.18 & 0.67 \\
\hline \multicolumn{7}{|l|}{ Type of seizures } \\
\hline Simple partial & 24 & 23.08 & 29 & 19.33 & & \\
\hline Complex partial & 26 & 25.00 & 26 & 17.33 & & \\
\hline Generalized & 54 & 51.92 & 95 & 63.33 & 3.54 & 0.17 \\
\hline \multicolumn{7}{|l|}{ Etiology } \\
\hline Idiopathic & 49 & 47.12 & 114 & 76.00 & & \\
\hline Symptomatic & 55 & 52.88 & 36 & 24.00 & 22.29 & $<0.001$ \\
\hline
\end{tabular}

The genotypic distributions of the $A B C B 1$ rs1045642 and rs2032582 and $A B C C 2$ rs2273697 and rs717620 polymorphisms are summarized in Table 3. The CC, CT, and TT genotypes of $A B C C 2$ rs 717620 were significantly different between the drug-responsive and drug-resistant epilepsy groups $\left(\chi^{2}=6.01, \mathrm{P}=0.04\right)$. However, no significant differences were found in the genotypic frequencies of $A B C B 1$ rs1045642 $\left(\chi^{2}=1.61, \mathrm{P}=0.45\right)$ and rs 2032582 $\left(\chi^{2}=0.22, \mathrm{P}=0.90\right)$ and $A B C C 2 \mathrm{rs} 2273697\left(\chi^{2}=0.24, \mathrm{P}=0.89\right)$ between the two study groups. 


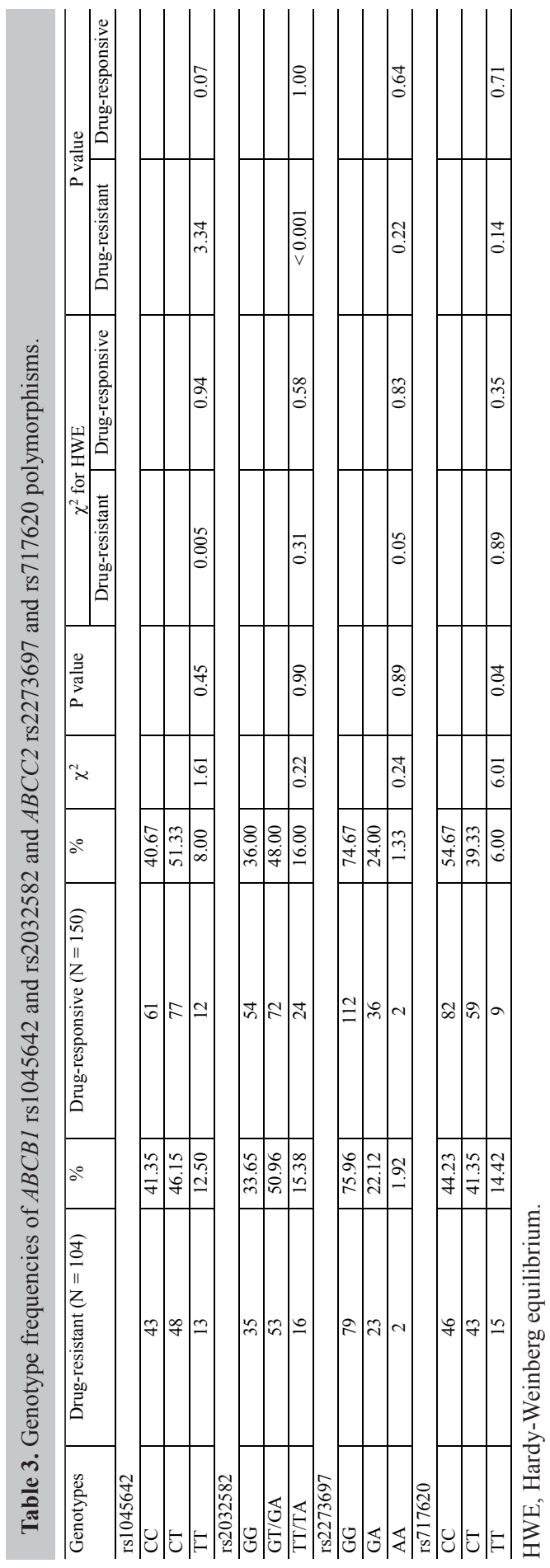

Genetics and Molecular Research 15 (4): gmr15048752 
The associations between the $A B C B 1$ rs 1045642 and rs2032582 and $A B C C 2$ rs2273697 and rs717620 polymorphisms and risk of drug-resistant epilepsy are summarized in Table 4. Logistic regression analysis indicated that the TT genotype of $A B C B 1$ rs717620 was associated with a higher risk of drug-resistant epilepsy compared to the $\mathrm{CC}$ genotype $(\mathrm{OR}=2.97,95 \% \mathrm{CI}=$ 1.11-8.29). The TT genotype of $A B C B 1$ rs717620 was correlated with an increased risk of drugresistant epilepsy $(\mathrm{OR}=2.64,95 \% \mathrm{CI}=1.03-7.13)$ compared to the $\mathrm{CC}+\mathrm{CT}$ genotype in the recessive model. However, no significant correlation was found between the $A B C B 1$ rs1045642 and rs2032582 and ABCC2 rs2273697 polymorphisms and risk of drug-resistant epilepsy.

An analysis of the interactions between the demographic and clinical variables (environment) and the $A B C B 1$ rs1045642 and rs2032582 and $A B C C 2$ rs2273697 and rs717620 polymorphisms revealed that this interaction did not influence the risk of drug-resistant epilepsy.

Table 4. Association between $A B C B 1$ rs1045642 and rs2032582 and $A B C C 2$ rs2273697 and rs717620 polymorphisms and risk of drug-resistant epilepsy.

\begin{tabular}{|c|c|c|c|c|c|c|}
\hline Genotypes & Drug-resistant $(\mathrm{N}=104)$ & $\%$ & Drug-responsive $(\mathrm{N}=150)$ & $\%$ & OR $(95 \% \mathrm{CI})^{1}$ & $\mathrm{P}$ value \\
\hline \multicolumn{7}{|l|}{ rs1045642 } \\
\hline \multicolumn{7}{|l|}{ Codominant } \\
\hline$\overline{\mathrm{CC}}$ & 43 & 41.35 & 61 & 40.67 & 1.0 (Ref.) & - \\
\hline$\overline{\mathrm{CT}}$ & 48 & 46.15 & 77 & 51.33 & $0.88(0.50-1.56)$ & 0.65 \\
\hline TT & 13 & 12.50 & 12 & 8.00 & $1.54(0.58-4.07)$ & 0.33 \\
\hline \multicolumn{7}{|l|}{ Dominant } \\
\hline$\overline{\mathrm{CC}}$ & 43 & 41.35 & 61 & 40.67 & 1.0 (Ref.) & - \\
\hline $\mathrm{CT}+\mathrm{TT}$ & 61 & 58.65 & 89 & 59.33 & $0.97(0.57-1.67)$ & 0.91 \\
\hline \multicolumn{7}{|l|}{ Recessive } \\
\hline $\mathrm{CC}+\mathrm{CT}$ & 91 & 87.5 & 138 & 92 & 1.0 (Ref.) & - \\
\hline TT & 13 & 12.5 & 12 & 8 & $1.64(0.66-4.12)$ & 0.24 \\
\hline \multicolumn{7}{|l|}{ rs2032582 } \\
\hline \multicolumn{7}{|l|}{ Codominant } \\
\hline$\overline{\mathrm{GG}}$ & 35 & 33.65 & 54 & 36.00 & 1.0 (Ref.) & - \\
\hline$\overline{\text { GT/GA }}$ & 53 & 50.96 & 72 & 48.00 & $1.14(0.63-2.06)$ & 0.65 \\
\hline TT/TA & 16 & 15.39 & 24 & 16.00 & $1.03(0.44-2.35)$ & 0.90 \\
\hline \multicolumn{7}{|l|}{ Dominant } \\
\hline$\overline{\mathrm{GG}}$ & 35 & 33.65 & 54 & 36 & 1.0 (Ref.) & - \\
\hline$\overline{\mathrm{GT} / \mathrm{GA}+\mathrm{TT} / \mathrm{TA}}$ & 69 & 66.35 & 96 & 64 & $1.11(0.63-1.95)$ & 0.70 \\
\hline \multicolumn{7}{|l|}{ Recessive } \\
\hline$\overline{\mathrm{GG}+\mathrm{GT} / \mathrm{GA}}$ & 88 & 84.61 & 126 & 84 & 1.0 (Ref.) & - \\
\hline TT/TA & 69 & 15.39 & 96 & 64 & $1.03(0.67-1.59)$ & 0.89 \\
\hline \multicolumn{7}{|l|}{ rs2273697 } \\
\hline \multicolumn{7}{|l|}{ Codominant } \\
\hline$\overline{\mathrm{GG}}$ & 79 & 75.96 & 112 & 74.67 & 1.0 (Ref.) & - \\
\hline GA & 23 & 22.12 & 36 & 24.00 & $0.91(0.47-1.71)$ & 0.75 \\
\hline $\mathrm{AA}$ & 2 & 1.92 & 2 & 1.33 & $1.42(0.10-19.90)$ & 0.89 \\
\hline \multicolumn{7}{|l|}{ Dominant } \\
\hline$\overline{\mathrm{GG}}$ & 79 & 75.96 & 112 & 74.67 & 1.0 (Ref.) & - \\
\hline $\mathrm{GA}+\mathrm{AA}$ & 25 & 24.04 & 38 & 25.33 & $0.93(0.50-1.73)$ & 0.81 \\
\hline \multicolumn{7}{|l|}{ Recessive } \\
\hline $\mathrm{GG}+\mathrm{GA}$ & 102 & 98.08 & 148 & 98.67 & 1.0 (Ref.) & - \\
\hline $\mathrm{AA}$ & 2 & 1.92 & 2 & 1.33 & $1.45(0.10-20.29)$ & 0.71 \\
\hline \multicolumn{7}{|l|}{ rs 717620} \\
\hline \multicolumn{7}{|l|}{ Codominant } \\
\hline$\overline{\mathrm{CC}}$ & 46 & 44.23 & 82 & 54.67 & 1.0 (Ref.) & - \\
\hline CT & 43 & 41.35 & 59 & 39.33 & $1.30(0.74-2.29)$ & 0.34 \\
\hline TT & 15 & 14.42 & 9 & 6.00 & $2.97(1.11-8.29)$ & 0.04 \\
\hline \multicolumn{7}{|l|}{ Dominant } \\
\hline $\mathrm{CC}$ & 46 & 44.23 & 82 & 54.67 & 1.0 (Ref.) & - \\
\hline$\overline{\mathrm{CT}+\mathrm{TT}}$ & 58 & 55.77 & 68 & 45.33 & $1.52(0.89-2.60)$ & 0.10 \\
\hline \multicolumn{7}{|l|}{ Recessive } \\
\hline$\overline{\mathrm{CC}+\mathrm{CT}}$ & 89 & 85.58 & 141 & 94 & 1.0 (Ref.) & - \\
\hline TT & 15 & 14.42 & 9 & 6 & $2.64(1.03-7.13)$ & 0.02 \\
\hline
\end{tabular}

${ }^{1}$ Adjusted for age, sex and etiology. $\mathrm{OR}=$ odds ratio; $\mathrm{CI}=$ confidence interval.

Genetics and Molecular Research 15 (4): gmr15048752 


\section{DISCUSSION}

In this study, we attempted to evaluate the relationship between the $A B C B 1$ rs 1045642 and rs2032582 and $A B C C 2$ rs2273697 and rs717620 polymorphisms and risk of drug-resistant epilepsy; the results revealed that the TT genotype of the $A B C C 2$ rs 717620 polymorphism is significantly associated with the risk of drug-resistant epilepsy compared to the wild-type genotype.

Multidrug resistant protein 2, encoded by $A B C C 2$, is a multidrug transporter distributed in the blood-brain barrier, endothelial cells, astrocytes, and the surfaces of some neurons (König et al., 2013). Multidrug transporters regulate the two-way transfer balance of drugs in the blood and brain tissues to influence the drug concentration in the brain tissue, thereby influencing its resistance to antiepileptic drugs (Glauser and Pippenger, 2000). Previous studies have indicated that multidrug transporters could influence the efficacy of antiepileptic drugs (Zimprich et al., 2004; Ufer et al., 2009). Therefore, the $A B C C 2$ expression could influence the mechanism of transport of antiepileptic drugs in the brain tissues (Nies et al., 2004). A SNP is an insertion, deletion, or substitution of nucleic acid bases leading to a polymorphism in the gene sequence (Friedberg, 2003). Genetic polymorphisms can change the structure and quantity of the gene product, ultimately affecting the function of the product. Polymorphisms in $A B C C 2$ could influence the expression of this protein, therein affecting its response or resistance to antiepileptic drugs.

Several previous studies have reported an association between the $A B C C 2$ rs 2273697 and rs717620 polymorphisms and risk of drug-resistant epilepsy, but with conflicting results (Seo et al., 2008; Kwan et al., 2011; Hilger et al., 2012; Qu et al., 2012; Sporis et al., 2013; Subenthiran et al., 2013a; Escalante-Santiago et al., 2014; Ma et al., 2014). Qu et al. (2012) revealed a significant association between the $A B C C 2$ rs 2273697 and rs 717620 polymorphisms and resistance to antiepileptic drugs in Chinese epileptic patients. Subenthiran et al. (2013a) indicated a correlation between the $A B C C 2$ rs2273697 and rs717620 polymorphisms and resistance to antiepileptic drugs in a study comprising 152 and 162 anti-epileptic drug-responsive and-resistant patients, respectively (Subenthiran et al., 2013a). Ma et al. (2014) reported a possible correlation between the $A B C C 2$ rs2273697 polymorphism and resistance to antiepileptic drugs in 453 Chinese Han patients with epilepsy. However, other studies have reported that the $A B C C 2$ rs2273697 and rs717620 polymorphisms were not associated with resistance to antiepileptic drugs (Seo et al., 2008; Kwan et al., 2011; Hilger et al., 2012; Sporis et al., 2013). In this study, we reported a significant correlation between the $A B C C 2$ rs 717620 polymorphism and resistance to antiepileptic drugs. The discrepancies among these results may be attributed to differences in the sample populations and sizes, etiology of epilepsy, and patient selection criteria.

The results of this study are subject to two limitations. First, the patients were selected from a single region in China; therefore, the sample may not be representative of the general population. However, the genotype frequencies of the $A B C B 1$ and $A B C C 2$ polymorphisms were in accordance with the HWE, indicating that the samples could be representative of the general population. Second, the sample size was quite small, resulting in low statistical power to compare the differences between groups.

In conclusion, our study suggests that the $A B C C 2$ rs717620 polymorphism is associated with antiepileptic drug resistance in Chinese patients with epilepsy. Further studies with larger sample sizes and subjects with diverse ethnic backgrounds are required to confirm the mechanism by which the $A B C B 1$ and $A B C C 2$ polymorphisms resist antiepileptic drugs.

Genetics and Molecular Research 15 (4): gmr15048752 


\section{Conflicts of interest}

The authors declare no conflict of interest.

\section{ACKNOWLEDGMENTS}

Research supported by grants from the Health and Family Planning Commission of Hubei Province Scientific Research Project (\#WJ2015MA007) and the Wuhan Science and Technology Bureau Scientific Research Project (\#2015060101010047).

\section{REFERENCES}

Akamine Y, Yasui-Furukori N, Ieiri I and Uno T (2012). Psychotropic drug-drug interactions involving P-glycoprotein. CNS Drugs 26: 959-973. http://dx.doi.org/10.1007/s40263-012-0008-z

Begley DJ (2004). ABC transporters and the blood-brain barrier. Curr. Pharm. Des. 10: 1295-1312. http://dx.doi. org/10.2174/1381612043384844

Escalante-Santiago D, Feria-Romero IA, Ribas-Aparicio RM, Rayo-Mares D, et al. (2014). MDR-1 and MRP2 gene polymorphisms in Mexican epileptic pediatric patients with complex partial seizures. Front. Neurol. 5: 184. http:// dx.doi.org/10.3389/fneur.2014.00184

Friedberg EC (2003). DNA damage and repair. Nature 421: 436-440.http://dx.doi.org/10.1038/nature01408

Giussani G, Canelli V, Bianchi E, Erba G, et al.; EPIRES Group (2016). Long-term prognosis of epilepsy, prognostic patterns and drug resistance: a population-based study. Eur. J. Neurol. 23: 1218-1227. http://dx.doi.org/10.1111/ ene. 13005

Glauser TA and Pippenger CE (2000). Controversies in blood-level monitoring: reexamining its role in the treatment of epilepsy. Epilepsia 41 (Suppl 8): S6-S15.http://dx.doi.org/10.1111/j.1528-1157.2000.tb02950.x

Guo Y, Yan KP, Qu Q, Qu J, et al. (2015). Common variants of KCNJ10 are associated with susceptibility and anti-epileptic drug resistance in Chinese genetic generalized epilepsies. PLoS One 10: e124896.http://dx.doi.org/10.1371/journal. pone. 0124896

Hilger E, Reinthaler EM, Stogmann E, Hotzy C, et al. (2012). Lack of association between ABCC2 gene variants and treatment response in epilepsy. Pharmacogenomics 13: 185-190. http://dx.doi.org/10.2217/pgs.11.143

Huang C, Feng L, Li YH, Wang Y, et al. (2016). Clinical features and prognosis of epilepsy in the elderly in western China. Seizure 38: 26-31. http://dx.doi.org/10.1016/j.seizure.2016.03.011

Keangpraphun T, Towanabut S, Chinvarun Y and Kijsanayotin P (2015). Association of ABCB1 C3435T polymorphism with phenobarbital resistance in Thai patients with epilepsy. J. Clin. Pharm. Ther. 40: 315-319. http://dx.doi. org/10.1111/jept.12263

König J, Müller F and Fromm MF (2013). Transporters and drug-drug interactions: important determinants of drug disposition and effects. Pharmacol. Rev. 65: 944-966. http://dx.doi.org/10.1124/pr.113.007518

Kwan P, Wong V, Ng PW, Lui CH, et al. (2011). Gene-wide tagging study of the association between ABCC2, ABCC5 and ABCG2 genetic polymorphisms and multidrug resistance in epilepsy. Pharmacogenomics 12: 319-325. http:// dx.doi.org/10.2217/pgs. 10.183

Lazarowski A and Czornyj L (2011). Potential role of multidrug resistant proteins in refractory epilepsy and antiepileptic drugs interactions. Drug Metabol. Drug Interact. 26: 21-26. http://dx.doi.org/10.1515/dmdi.2011.006

Li SX, Liu YY and Wang QB (2015). ABCB1 gene C3435T polymorphism and drug resistance in epilepsy: evidence based on 8,604 subjects. Med. Sci. Monit. 21: 861-868.http://dx.doi.org/10.12659/MSM.894023

Ma CL, Wu XY, Zheng J, Wu ZY, et al. (2014). Association of SCN1A, SCN2A and ABCC2 gene polymorphisms with the response to antiepileptic drugs in Chinese Han patients with epilepsy. Pharmacogenomics 15: 1323-1336. http:// dx.doi.org/10.2217/pgs.14.89

Nies AT, Jedlitschky G, König J, Herold-Mende C, et al. (2004). Expression and immunolocalization of the multidrug resistance proteins, MRP1-MRP6 (ABCC1-ABCC6), in human brain. Neuroscience 129: 349-360. http://dx.doi. org/10.1016/j.neuroscience.2004.07.051

Pi X, Zhou L, Cui L, Liu A, et al. (2014). Prevalence and clinical characteristics of active epilepsy in southern Han Chinese. Seizure 23: 636-640.http://dx.doi.org/10.1016/j.seizure.2014.05.002

Genetics and Molecular Research 15 (4): gmr15048752 
Qu J, Zhou BT, Yin JY, Xu XJ, et al. (2012). ABCC2 polymorphisms and haplotype are associated with drug resistance in Chinese epileptic patients. CNS Neurosci. Ther. 18:647-651.

Qu J, Yang ZQ, Zhang Y, Mao CX, et al. (2015). Common variants of ATP1A3 but not ATP1A2 are associated with Chinese genetic generalized epilepsies. J. Neurol. Sci. 354: 56-62.http://dx.doi.org/10.1016/j.jns.2015.04.045

Seo T, Ishitsu T, Oniki K, Abe T, et al. (2008). ABCC2 haplotype is not associated with drug-resistant epilepsy. J. Pharm. Pharmacol. 60: 631-635.http://dx.doi.org/10.1211/jpp.60.5.0009

Sporis D, Bozina N, Basić S, Lovrić M, et al. (2013). Lack of association between polymorphism in ABCC2 gene and response to antiepileptic drug treatment in Croatian patients with epilepsy. Coll. Antropol. 37: 41-45.

Subenthiran S, Abdullah NR, Joseph JP, Muniandy PK, et al. (2013a). Linkage disequilibrium between polymorphisms of $\mathrm{ABCB} 1$ and $\mathrm{ABCC} 2$ to predict the treatment outcome of Malaysians with complex partial seizures on treatment with carbamazepine mono-therapy at the Kuala Lumpur Hospital. PLoS One 8: e64827. http://dx.doi.org/10.1371/ journal.pone. 0064827

Subenthiran S, Abdullah NR, Muniandy PK, Joseph JP, et al. (2013b). G2677T polymorphism can predict treatment outcome of Malaysians with complex partial seizures being treated with Carbamazepine. Genet. Mol. Res. 12: 59375944.http://dx.doi.org/10.4238/2013.November.26.3

Tang F, Zhu G, Jiao Z, Ma C, et al. (2014). The effects of medication education and behavioral intervention on Chinese patients with epilepsy. Epilepsy Behav. 37: 157-164.http://dx.doi.org/10.1016/j.yebeh.2014.05.017

Ufer M, Mosyagin I, Muhle H, Jacobsen T, et al. (2009). Non-response to antiepileptic pharmacotherapy is associated with the ABCC2 $-24 \mathrm{C}>\mathrm{T}$ polymorphism in young and adult patients with epilepsy. Pharmacogenet. Genomics 19: 353-362. http://dx.doi.org/10.1097/FPC.0b013e328329940b

Urry DW, Urry KD, Szaflarski W, Nowicki M, et al. (2009). Function and frustration of multi-drug ABC exporter protein and design of model proteins for drug delivery using protein hydration thermodynamics. Curr. Pharm. Des. 15: 2833-2867. http://dx.doi.org/10.2174/138161209788923787

Wang Y, Tang L, Pan J, Li J, et al. (2015). The recessive model of MRP2 G1249A polymorphism decrease the risk of drug-resistant in Asian Epilepsy: a systematic review and meta-analysis. Epilepsy Res. 112: 56-63.http://dx.doi. org/10.1016/j.eplepsyres.2015.02.007

Yu L, Liao WP, Yi YH and Qiu G (2015). ABCB1 G2677T/A polymorphism is associated with the risk of drug-resistant epilepsy in Asians. Epilepsy Res. 115: 100-108. http://dx.doi.org/10.1016/j.eplepsyres.2015.05.015

Zhou B, Huang Y, Wang J, Zou Z, et al. (2014). The aetiology of convulsive status epilepticus: a study of 258 cases in Western China. Seizure 23: 717-721.http://dx.doi.org/10.1016/j.seizure.2014.05.015

Zhou L, Cao Y, Long H, Long L, et al. (2015). ABCB1, ABCC2, SCN1A, SCN2A, GABRA1 gene polymorphisms and drug resistant epilepsy in the Chinese Han population. Pharmazie 70: 416-420.

Zimprich F, Sunder-Plassmann R, Stogmann E, Gleiss A, et al. (2004). Association of an ABCB1 gene haplotype with pharmacoresistance in temporal lobe epilepsy. Neurology 63: 1087-1089. http://dx.doi.org/10.1212/01. WNL.0000141021.42763.F6 